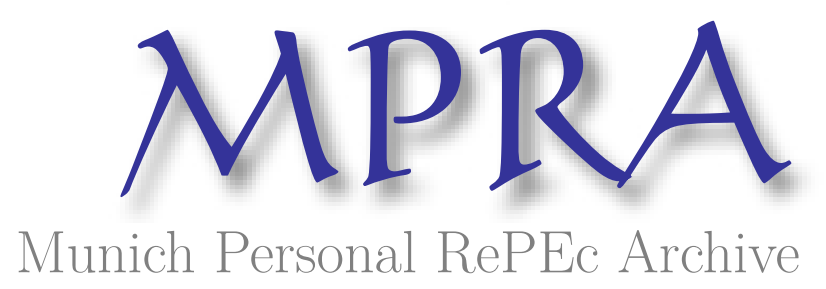

\title{
The Links between Economic Growth and Tax Revenue in Ghana: An Empirical Investigation
}

Njindan Iyke, Bernard and Takumah, Wisdom

University of South Africa, University of Cape Coast

1 October 2015

Online at https://mpra.ub.uni-muenchen.de/67281/

MPRA Paper No. 67281, posted 18 Oct 2015 08:08 UTC 
The Links between Economic Growth and Tax Revenue in Ghana: An Empirical Investigation

\author{
By \\ Wisdom Takuma \\ Department of Economics \\ University of Cape Coast \\ Private Mail Bag \\ 0233, Cape Coast \\ Ghana \\ Email: wtakumah@yahoo.com
}

\author{
And \\ Bernard Njindan Iyke \\ Department of Economics \\ University of South Africa \\ P. O. Box 392, UNISA \\ 0003, Pretoria \\ South Africa \\ Tel: $+27(0) 124334627$
}

Email: benitoflex@gmail.com / niykeb@unisa.ac.za

October 2015 


\title{
The Links between Economic Growth and Tax Revenue in Ghana: An Empirical Investigation
}

\begin{abstract}
This paper explores the causal influence of tax revenue on economic growth in Ghana. Our point of departure from the existing studies lies in the fact that we examine causality instead of the impact. The causality analysis performed in this paper builds on a multivariate setup, allowing for key control variables to intermediate the nexus between tax revenue and economic growth. Such a rich environment can overcome variable omission bias; thus allowing for efficient estimates of the test statistics of the Granger causality. In addition, we employed the Toda-Yamamoto test instead of the canonical Granger causality test to avoid pre-testing bias. Using a quarterly dataset which spans the period 1986Q1-2014Q4, we found strong evidence of unidirectional causal flow from tax revenue to economic growth in Ghana. This finding agrees with the existing finding that taxation can influence economic growth. The policy implication is quite clear. Ghana is a net borrower since the country regularly suffers from budget deficits. The policymaker can implement policies that enhance the tax scope in order to increase the revenue from taxation. For a country whose economy has a large share of black market activities, such a policy may be challenging to implement. Thus, such policies will require collective efforts from the policymaker and the players in the economy. To induce people to buy into these kinds of policies, the policymaker must first embrace accountability of the revenue raised from taxation. Productive government spending will appeal to the players of the Ghanaian economy whereas unproductive and unaccountable government spending will not.
\end{abstract}

\section{Keywords: Causality, Economic Growth, Tax Revenue, Ghana}

\section{JEL Codes: H2, O40}




\section{Introduction}

Tax policy can be regarded as the necessary component of economic policies for a country to sustain and strengthen its economic growth and global competitiveness. It provides countries with stable and predictable fiscal environment; thus, enabling them to accumulate funds to finance their social and physical infrastructural needs (see Romer and Romer 2010). Combined with economic growth, effective tax policies reduce long-term reliance on aid and ensure good governance by promoting the accountability of governments to their citizens (see Romer and Romer 2010). Nowadays, with the highly moving capital and specialized work, it is imperative that the tax structure be competitive in order to attract capital, specialized work and technology which are essential elements for maximizing economic growth.

The role of taxation in influencing economic growth is not only a major concern to the policymakers, tax specialists and administrators but has long been of interest to academics and researchers. The neoclassical growth model of Solow (1956) and Swan (1956) suggests that steady state growth is not affected by tax policy (i.e. tax policy has no impact on longrun economic growth). Yet, the endogenous growth theory, pioneered by Romer (1990), has produced growth models in which government spending and tax policies can have long-term or permanent growth effects.

The theoretical findings in the literature indicate that taxation can have both negative and positive effects on economic growth. The negative effect is due to the distortions in choices and effects of discouragement factors inherent in taxes (see, for example, Easterly and Rebelo 1993). The positive effect is indirectly due to the expenditures financed by the taxation (see Engen and Skinner 1996). Thus, the theory appears inconclusive on role of taxation in economic growth. The obvious way to proceed to investigate the exact nature of the taxationgrowth linkages is by taking the theory to the data (see Myles 2009). Most of the empirical studies on tax revenue and economic growth are mainly cross-country in nature (for example, 
see Leibfritz, Thornton and Bibbee 1997; Koester and Kormendi 1989; Levine and Renelt 1992) whose findings cannot be directly applied to Ghana, since these findings may not accurately and adequately reflect the Ghanaian experience.

That aside, the relatively older empirical studies, such as those of Engen and Skinner (1992; 1996), Easterly and Rebelo (1993), Alesina and Perotti (1996), Devarajan, Swaroop and Zou (1996), McDermott and Wescott (1996), Barro (1997), Leibfritz et al. (1997), Tanzi and Zee (1997), Skreb (1999), that analyze the impact of tax revenue on economic growth arrive at contradictory results; thus, reflecting the difficulty in establishing the role of taxation in economic growth. Though, the theory underlines especially a negative relationship between taxation and economic growth, the empirical research provide ambiguous results.

The evidence does not get better with even the most recent empirical studies. Indeed, studies such as Padovano and Galli (2001), Lee and Gordon (2004), Myles (2009), Arseneau et al. (2011), Mutascu and Danuletiu (2011), Ebrahimi and Vaillancourt (2012), Dackehag and Hansson (2012) obtained non-consensual results just as the theory suggests. The different results obtained by the available empirical studies do not permit the researcher to draw univocal conclusion about the impact of taxation on economic growth.

The conflicting nature of these findings may be due to: $(i)$ different definitions of state in different countries and periods (i.e. whether it is a central government or general government with extra-budgetary funds and local governments), which means different levels of taxation; (ii) problems of measuring of individual tax variables, such as marginal tax rates (see Easterly and Rebelo, 1993; Engen and Skinner, 1996); (iii) difficulties in sorting out the impact of individual tax variables on growth, because of complex interactions of fiscal variables (i.e. tax increase does not have to reduce growth if such increased taxes are used for financing those forms of public investments that will increase productivity of private 
investments, thus stimulating growth); (iv) difficulties in separating the impact on growth of other economic variables from the impact of fiscal variables only; $(v)$ lack of empirical data enabling unambiguous acceptance or rejection of a conclusion of some theoretical model.

Although the exact impact of taxation on economic growth is very important for policymaking, the nature of the causal links between these two macroeconomic variables is equally crucial. If there is a causal flow from taxation to economic growth, this will suggest that policymakers can count on taxation as a fiscal policy tool to influence economic activities. Indeed, this is the policy implication of Keynesian theories. However, if there is no causal flow between taxation and economic growth -- which is the implied policy implication of the Classical growth theories in the long run -- then taxation as a fiscal policy will be ineffective. In spite of this obvious policy importance of the causal flow between taxation and economic growth, the literature has remained very discreet about it. In this paper, we attempt to fill this chasm by documenting the nature of the causal linkages between taxation and economic growth in Ghana. In doing so, we add to the literature in two ways: (i) to the best of our knowledge, this is the first paper to investigate the causal links between taxation and economic growth for a developing country, (ii) we shift the emphasis, as replete in the literature, from the "impact" to the "causal flow", thus shedding new insight into the taxationgrowth debate. This shift in paradigm, we suppose, will improve policymaking especially in developing countries.

The causality analysis performed in this paper builds on a multivariate setup, allowing for key control variables such as capital, labour, government expenditure, and inflation to intermediate the nexus between tax revenue and economic growth. Such a rich environment can overcome variable omission bias; thus allowing for efficient estimates of the test statistics of the Granger causality. In addition, we employed the Toda-Yamamoto test instead of the canonical Granger causality test to avoid pre-testing bias. In the next section, we present the 
theoretical and empirical models, the econometric techniques, and the data. Then, in Section 3, we present the empirical results. Section 4 provides the concluding remarks.

\section{The Methodology}

\subsection{Theoretical Model Specification}

The neoclassical growth model of Solow (1956) and Swan (1956) provides the basic theoretical connection between economic growth and tax revenue. To see why, consider the following Solow (or Solow-Swan) model, which explains total output in an economy $\left(Y_{t}\right)$ as product of the combination of capital $\left(K_{t}\right)$ and labour $\left(L_{t}\right)$

$Y_{t}=f\left(K_{t}, L_{t}\right)$

where $Y_{t}$ is the total output, $f$ is the technology which transforms $K_{t}$ and $L_{t}$ into $Y_{t}$, and $t$ is the time subscript.

The social planner will want to know what proportion $Y_{t}$, the total economy-wide output, is attributed to labour and capital. In his seminal paper, Solow (1956) demonstrates that after accounting for the proportion of total output attributed to labour and capital, the remaining portion is due to what he calls total factor productivity (TFP). Thus, the growth in the total output of an economy is attributed to the growth in labour, capital, and TFP, according to Solow's growth accounting framework. The TFP growth is considered as the effect of exogenous technological progress in this neoclassical growth model, which can also be reflected in increasing productive efficiency. To account for this TFP in output, Eq. (1) is restated as

$Y_{t}=f\left(K_{t}, L_{t}, A_{t}\right)$ 
where $A_{t}$ is total factor productivity. If we assume that the functional form of $E q$. (2) is Cobb-Douglas form, then we have

$Y_{t}=A_{t} K_{t}^{\alpha} L_{t}^{\beta}$

where $\alpha$ and $\beta$ are shares of capital and labour, respectively.

Solow (1956) argues that the Cobb-Douglas production function is convenient because it exhibits constant returns to scale. The key point to note here is that $A_{t}$ is not constant but varies over time. This assumption is necessary in order to allow factors such as foreign direct investment, investment in research and development, tax revenue among others to influence TFP. The assumption that the functional form of Eq. (2) is Cobb-Douglas is widely used in the literature (see, for instance, Ram and Ramsey 1989; Fosu 1990; Mansouri 2005; Fosu and Magnus 2006; Fosu and Aryeetey 2008).

\subsection{Empirical Model Specification}

This paper adopts the basic neoclassical Solow growth model but departs from this model by allowing technology, $A_{t}$, to evolve over time. The majority of the literature on economic growth indicates that there are a large number of variables that can affect the TFP $\left(A_{t}\right)$ in $E q$. (3). Following studies such as Mansouri (2005), Fosu and Magnus (2006), we augment Eq. (3) as follows

Let $A_{t}=f\left(T T R_{t}, F D I_{t}, G O V_{t}, C P I_{t}\right)=T T R_{t}^{\delta_{1}} F D I_{t}^{\delta_{2}} G O V_{t}^{\delta_{3}} C P I_{t}^{\delta_{4}}$

Then by substituting Eq. (4) into Eq. (3), we arrive at the following extended form

$$
Y_{t}=\mu K_{t}^{\alpha} L_{t}^{\beta} T T R_{t}^{\delta_{1}} F D I_{t}^{\delta_{2}} G O V_{t}^{\delta_{3}} C P I_{t}^{\delta_{4}}
$$


where $T T R_{t}$ is tax revenue, GOV is government expenditure, $F D I_{t}$ is foreign direct investment, $C P I_{t}$ is consumer price index inflation, and $\delta_{i}$ are the share of these inputs in the total output.

The standard procedure for estimating Eq. (5) is by first log-linearizing it. By taking the natural logarithm of Eq. (5), we arrive at the following specification

$$
Y_{t}=\ln \mu+\alpha \ln K_{t}+\beta \ln L_{t}+\delta_{1} \operatorname{lnTTR}_{t}+\delta_{2} \ln F D I_{t}+\delta_{3} \ln G O V_{t}+\delta_{4} \ln C P I_{t}+\epsilon_{t}
$$

By letting $\ln \mu=\gamma$, then $E q$. (6) becomes

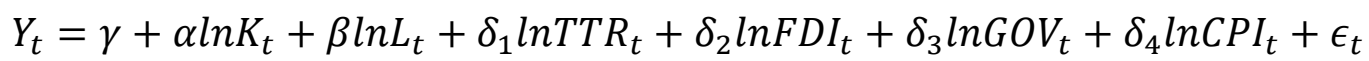

where $\ln$ is the natural logarithm operator; and $\epsilon_{t}$ denotes the unobserved determinants of the total output, $Y_{t}$, which is white-noise.

\subsection{Variable Definition and Justification}

\subsubsection{Economic Growth}

Economic growth is defined as the sustained increases in a country's gross domestic product overtime. The existing literature suggests that real gross domestic product can be used as an efficient measure of economic growth. Real GDP is an inflation adjusted measure that reflects the value of all goods and services produced in a given year expressed in the base year prices. Studies such as, Kargbo and Adamu (2010), and Erbaykal and Okuyan (2008) used Real GDP as a measure of economic growth in their empirical analysis.

\subsubsection{Tax Revenue}

Tax revenue is the income gained by government through taxation. Tax revenue is used to finance government expenditure and to redistribute wealth which translates into financing 
development of a country (Ola 2001; Jhingan 2004; Bhartia 2009). Musgrave and Musgrave (2004) state that tax has micro effects on the distribution of income and the efficiency of resource use as well as macro effect on the level of capacity output, employment, prices, and growth (see Mascagni, Moore, and McCluskey 2014).

\subsubsection{Foreign Direct Investment (FDI)}

FDI has been widely recognized as a growth-enhancing factor in developing countries (see Borensztein et al. 1998). Therefore an increase in FDI is expected to lead to an increase in total investment, and hence increase in total output and its rate of growth. The empirical literature examining the impact of FDI on growth has provided more or less consistent findings affirming a significant positive link between the two variables (see Borensztein et al. 1998; Hermes and Lensink 2000; Lensink and Morrissey 2006; Esso 2010).

\subsubsection{Gross Fixed Capital Formation (K)}

Gross Fixed Capital Formation is used as a proxy for capital stock in this paper. It has been used in similar fashion in studies such as Aryeetey and Fosu (2005), Mansouri (2005), Naguib (2008), and Kargbo and Adamu (2009). Gross Fixed Capital Formation as a percentage of GDP (a proxy for capital stock) exerts positive effects on real GDP growth. The higher the rate of investment, the higher the growth rate of the economy, all things being equal (see Aryeetey and Fosu 2005). This is in line with both the neoclassical and endogenous growth predictions.

\subsubsection{Government Expenditure}

The ratio of government expenditure to GDP $(G O V)$ enters the model as a policy variable, since an increase in government expenditure, especially on productive activities such as road 
construction, and provision of electricity, can boost economic growth (see Easterly and Rebelo, 1993; Hansson and Henrekson 1994; Fölster, and Henrekson 2006; Afonso and Furceri 2010; Bergh and Karlsson 2010). Government expenditure is also included in our model to complete the components of the GDP. Government expenditure, according to the Keynesian proposition is expected to raise economic growth.

\subsubsection{Consumer Price Index Inflation (CPI)}

Consumer Price Index measures the weighted average prices of consumer goods and services. It is calculated by taking the price changes for each item in the predetermined basket of goods and averaging them. Changes in CPI are used to assess price changes associated with the cost of living. The CPI is used to determine periods of inflation or deflation. This is because large rises in the CPI during a short period of time typically denotes periods of high inflation which is a reflection of macroeconomic instability. A high rate of inflation is generally harmful to growth because it raises the cost of borrowing and thus lowers the rate of capital investment. Inflation is therefore used as an indicator to capture macroeconomic instability (Barro 1995; Sarel 1995; De Gregorio 1996; Asiedu and Lien 2004; Erbaykal and Okuyan 2008).

\subsubsection{Labour Force $(L)$}

Labour force (labour participation rate) is chosen instead of population growth because it denotes a proportion of the total population aged between fifteen (15) and sixty-five (65) years, which is precisely the active and productive population in the country. Solow (1956) and Swan (1956) advise that labour force should be included in a neoclassical growth model because of its impact on general productivity. It has been proven empirically that labour force is a good measure of economic growth (see Domar 1946; Solow 1956; Swan 1956). 


\subsection{Testing for Causality}

In this section, we discuss the econometric technique that is used to examine the causal relationships between tax revenue and economic growth in Ghana. This technique is the Toda-Yamamoto test for causality advanced by Toda and Yamamoto (1995). The test involves the following steps. First, we examine the stationarity properties of our time series. In this paper, we make use of the Augmented Dickey-Fuller $(A D F)$ and the Phillips-Perron $(P P)$ tests to check for the order of integration of our variables. Second, we fit a vector autoregressive (VAR) model for $E q$. (7) and determine the optimal lag to be included in the parsimonious VAR model using the standard information criteria. Third, we undertake some diagnostic tests to ensure that our VAR is structurally and dynamically stable and is free of serial correlation problems. Fourth, we fit an augmented VAR model which is of order "optimal lag plus maximum order of integration in the time series". Finally, we perform the causality test by estimating a modified Wald statistic for the lagged covariates in our augmented VAR model.

\subsubsection{Unit Roots Test}

Testing for unit roots is very critical in time series analysis, mainly because relationships involving non-stationary time series are often spurious. Spurious relationships are conditions whereby the estimated results show very high and significant relationships among variables when in fact no relationship exist. Emphasizing the dangers of not testing for unit roots, Stock and Watson (1988) demonstrate that the usual test statistics (for example, $t, F, D W$ and $R^{2}$ ) do not have standard distributions if some of the variables in the model have unit roots.

Apart from the fact that we have to examine the stationarity properties of the variables in order to obviate spurious relationships, the Toda-Yamamoto test we utilize requires that we test for stationarity. In this paper, we test the stationarity properties of the variables with the 
$A D F$ and the $P P$ tests, two of the most widely applied unit root tests. ${ }^{1}$ These tests are very similar except that they differ with respect to the way they adjust for autocorrelation in the residuals (see Phillips and Perron 1988). In particular, the $P P$ test is nonparametric and generalizes the $A D F$ process by allowing for less restrictive assumptions for the time series in question. It has been observed that the $A D F$ test has low power in small samples (see Cheung and Lai 1993). Moreover, the $A D F$ is very sensitive to the lag length chosen. Thus, we employ the $P P$ test as a robustness check of our $A D F$ results. The regression specification for both tests is of the form

$\Delta X_{t}=\alpha+\delta t+\rho X_{t-1}+\sum_{i=1}^{p} \lambda_{i} \Delta X_{t-i}+\varepsilon_{t}$

where $X_{t}$ represents the series at time $t ; \Delta$ is the first-difference operator; $\alpha, \delta, \rho$, and $\lambda$ are parameters to be estimated and $\varepsilon$ is the white-noise disturbance term. The $A D F$ and the $P P$ tests evaluate the null hypothesis that a series contains unit roots (non-stationary) against the alternative hypothesis of no unit roots (stationary). That is, $H_{0}: \rho=0$ against $H_{0}: \rho \neq 0$.

We can reject the null hypothesis of unit roots if the $A D F$ and the $P P$ statistics are greater than the tabulated values for these tests. For the $A D F$ test, we select the optimal lag to be included in the regression using the Swartz Bayesian Information Criterion (SBC). For the PP test, we determine the optimal bandwidth using the Andrews (1991) bandwidth with Bartlett kernel density function.

\subsubsection{Toda-Yamamoto Test for Causality}

The test for Granger causality, as developed in the seminal paper of Granger (1969), in vector autoregressive (VAR) setting requires the researcher to first establish the order of integration

\footnotetext{
${ }^{1}$ The $A D F$ and the $P P$ tests were developed by Said and Dickey (1984), and Phillips and Perron (1988), respectively.
} 
of the variables under consideration. In cases where the variables are integrated of order one [i.e. I(1) processes], the researcher must establish whether the variables are cointegrated, before the Granger causality test can be undertaken. Yet most of the test for non-stationarity and non-cointegration are known to have low power against the alternative hypotheses of stationarity and cointegration (see Toda and Yamamoto 1995). This connotes that the traditional Granger causality test, which entails testing for unit root and cointegration before performing the test for causality, is exposed to pretesting bias (Toda and Yamamoto 1995). This argument is supported by He and Maekawa (1999), who point out that testing for causality using $F$-statistics, when one or both time series are non-stationary, can lead to spurious causality.

As advanced by Toda and Yamamoto (1995), the spurious causality problems imbue in the traditional Granger causality test can be circumvented by fitting an augmented VAR model of order "optimal lag plus maximum order of integration in the variables". This technique, they argue, ensures that the test statistic for the causality test has a standard asymptotic distribution. Following Yamada (1998), we can perform the Toda-Yamamoto causality test in a bivariate setting by fitting the following augmented $\operatorname{VAR}\left(m+d_{\max }\right)$ model

$$
\begin{aligned}
& y_{t}=\gamma_{0}+\sum_{i=1}^{m} \gamma_{1 i} y_{t-i}+\sum_{i=m+1}^{m+d_{\max }} \gamma_{2 i} \mathrm{y}_{t-i}+\sum_{i=1}^{m} \varphi_{1 i} x_{t-i}+\sum_{i=m+1}^{m+d_{\max }} \varphi_{2 i} x_{t-i}+u_{1 t} \\
& x_{t}=\Theta_{0}+\sum_{i=1}^{m} \Theta_{1 i} x_{t-i}+\sum_{i=m+1}^{m+d_{\max }} \Theta_{2 i} x_{t-i}+\sum_{i=1}^{m} \delta_{1 i} y_{t-i}+\sum_{i=m+1}^{m+d_{\max }} \delta_{2 i} y_{t-i}+u_{2 t}
\end{aligned}
$$

where $y_{t}$ and $x_{t}$ are the series under consideration; $\delta, \gamma, \Theta$ and $\varphi$ are the parameters of the model; $u_{1}$ and $u_{2}$ are the white-noise disturbances. 
From $E q$. (9), we can say that $x_{t}$ causes $y_{t}$ if $\varphi_{1 i} \neq 0, \forall i=1,2, \ldots, m$. Similarly, in Eq. (3), we can say that $y_{t}$ causes $x_{t}$ if $\delta_{1 i} \neq 0, \forall i=1,2, \ldots, m$. The test statistics for these hypotheses follow a chi-squared distribution. Assume we are testing the hypothesis $\delta_{1 i}=$ $0, \forall i=1,2, \ldots, m$, for example, and let $\delta=\operatorname{vec}\left(\delta_{1}, \delta_{2}, \ldots, \delta_{m}\right)$ be a vector of $m V A R$ parameters. For a suitably selected $Z$, Toda and Yamamoto (1995) demonstrate that the modified Wald-statistic for testing this hypothesis is of the form

$W=T\left(\hat{\delta}^{\prime} Z^{\prime}\left(Z \hat{\Sigma}_{u}^{\prime} Z^{\prime}\right)^{-1} Z \hat{\delta}\right)$

where $\hat{\delta}$ is the OLS estimate of $\delta ; \hat{\Sigma}_{u}$ is a consistent estimate of the variance-covariance matrix of $\sqrt{T}(\hat{\delta}-\delta) ; T$ is the sample size. $W$, the test statistic, is chi-squared distributed with $m$ degrees of freedom. This bivariate augmented VAR model can be extended in our case to include all the variables. The steps for carrying out the Toda-Yamamoto causality test will be essentially the same for this extension.

\subsection{The Data}

Our data comes from two sources: The Bank of Ghana's Macroeconomic Time Series Database and the World Bank's World Development Indicators (2015). The data is quarterly and spans the period 1986Q1-2014Q4. The time span is not long enough. More so, the frequency of the original dataset is annual. To increase the sample size for our empirical analysis, we generated the quarterly data by deploying the Gandolfo (1980) algorithm. The choice of the data coverage is informed by the fact that it is challenging to get data below 1986 on key control variables in the tax-growth nexus. Besides, significant changes in the Ghanaian tax structure started with the tax reforms under the Structural Adjustment Programme (SAP) of 1986. It is, therefore, imperative that any meaningful empirical analysis of the tax-growth nexus should start from the year of these reforms. 


\section{The Results}

\subsection{Descriptive Statistics}

In this section, we report the descriptive statistics of the relevant variables used in this paper. These descriptive statistics include the mean, median, maximum, minimum, standard deviation, skewness, kurtosis, sum, sum squared deviation and number of observations. Table 1 presents these statistics. From Table 1, we can observe that all the variables have positive average values (i.e. mean and median). This is normal considering the series involved. In addition, the series have minimal deviations from their means as shown by their standard deviations. This gives an indication that the series have experienced slow growth rate (i.e. fluctuation) over the period 1986Q1-2014Q4. In terms of skewness, all of the variables are positively skewed.

Table 1: Summary Statistics of the Variables

\begin{tabular}{lccccccc}
\hline & GDP & TTR & GOV & FDI & CPI & K & L \\
\hline Mean & $2.45 \mathrm{E}+09$ & 511146 & $4.97 \mathrm{E}+08$ & $2.10 \mathrm{E}+08$ & 5.4959 & $8.73 \mathrm{E}+08$ & 2017142 \\
Median & $2.10 \mathrm{E}+09$ & 108359 & $2.80 \mathrm{E}+08$ & 34942263 & 4.4258 & $3.95 \mathrm{E}+08$ & 2057735 \\
Maximum & $5.16 \mathrm{E}+09$ & 201521 & $2.01 \mathrm{E}+09$ & $8.45 \mathrm{E}+08$ & 15.965 & $3.39 \mathrm{E}+09$ & 3084049 \\
Minimum & $8.15 \mathrm{E}+08$ & 9835.76 & 2682519 & 648148.1 & 2.0493 & 95966892 & 890497 \\
Std. Dev. & $1.14 \mathrm{E}+09$ & 677525 & $5.37 \mathrm{E}+08$ & $3.05 \mathrm{E}+08$ & 3.1382 & $9.30 \mathrm{E}+08$ & 472806 \\
Skewness & 0.957432 & 1.15582 & 1.083408 & 1.160832 & 1.2314 & 1.393905 & 0.143369 \\
Kurtosis & 2.893531 & 2.80339 & 3.379754 & 2.542290 & 4.2258 & 3.602370 & 2.276312 \\
Sum & $2.84 \mathrm{E}+11$ & $5.93 \mathrm{E}+08$ & $5.76 \mathrm{E}+10$ & $2.43 \mathrm{E}+10$ & 637.53 & $1.01 \mathrm{E}+11$ & $2.34 \mathrm{E}+08$ \\
$\begin{array}{l}\text { Sum Sq. Dev } \\
\text { Subservations }\end{array}$ & $1.48 \mathrm{E}+20$ & $5.28 \mathrm{E}+15$ & $3.32 \mathrm{E}+19$ & $1.07 \mathrm{E}+19$ & 1132.5 & $9.94 \mathrm{E}+19$ & $2.57 \mathrm{E}+10$ \\
\hline $\begin{array}{l}\text { Note: Max denotes Maximum, Min denotes Minimum, Std. Dev. denotes Standard Deviation, while Sum Sq. } \\
\text { Dev. denotes Sum of Squared Deviation. }\end{array}$ & & & & &
\end{tabular}




\subsection{Evidence of Unit Roots in the Variables}

As a preliminary analysis, we examine the unit root properties of the variables employed in this paper. To do this, we utilize the Augmented Dickey-Fuller $(A D F)$ and Phillips-Perron $(P P)$ tests. Lag selection and bandwidth form vital parts of the $A D F$ test and the PP test, respectively. For the $A D F$ test, we use the Schwartz Bayesian Criterion (SBC) to select the optimal lag. In the case of the PP test, we use the Andrews (1991) bandwidth with Bartlett kernel density function. We include both the intercept and the trend component in the augmented $D F$ regression for the two tests. Table 2 shows the results for the unit root tests on the variables at levels. Clearly, the null hypothesis of unit root is accepted at the expense of the alternative, in all the cases and for the two tests, at the conventional levels of significance. This shows that the variables are non-stationary or have unit roots at their levels.

Table 2: Tests for Unit Roots at Levels with Intercept and Trend

\begin{tabular}{lllllll}
\hline Variable & $\boldsymbol{A D F}$ & P-value & {$[$ Lag] } & $\boldsymbol{P P}$ & P-value & {$[\mathbf{B W}]$} \\
\hline $\ln \mathrm{GDP}$ & 0.015 & $(0.996)$ & {$[1]$} & 0.994 & $(0.999)$ & {$[1]$} \\
$\ln \mathrm{K}$ & 2.748 & $(1.000)$ & {$[1]$} & -0.902 & $(0.951)$ & {$[3]$} \\
$\ln \mathrm{L}$ & -3.076 & $(0.117)$ & {$[1]$} & -0.826 & $(0.808)$ & {$[7]$} \\
$\ln \mathrm{TTR}$ & -1.354 & $(0.869)$ & {$[1]$} & -0.726 & $(0.968)$ & {$[7]$} \\
$\ln \mathrm{FDI}$ & -1.614 & $(0.781)$ & {$[0]$} & -1.474 & $(0.833)$ & {$[6]$} \\
$\ln \mathrm{GOV}$ & 0.144 & $(0.997)$ & {$[3]$} & 2.181 & $(1.000)$ & {$[7]$} \\
$\ln \mathrm{CPI}$ & -2.948 & $(0.104)$ & {$[2]$} & -3.404 & $(0.506)$ & {$[2]$} \\
\hline
\end{tabular}

Note: The block parenthesis contains the lag and the bandwidth. BW denotes bandwidth.

Since the variables are shown to have unit roots, we difference them once and re-conduct the unit root tests. The results of the unit root tests on the first-differenced variables are reported in Table 3. From Table 3, it is quite straight forward to state that all the variables are 
stationary or have no unit roots at the conventional levels of significance. That is, both the $A D F$ test and the $P P$ test reject the null hypothesis of unit roots in favour of the alternative (see Table 3). Therefore, the order of integration of the variables in our empirical model is one.

Table 3: Tests for Unit Root at First Difference with Intercept and Trend

\begin{tabular}{|c|c|c|c|c|c|c|}
\hline Variable & $A D F$ & P-value & [Lag] & $P P$ & P-value & [BW] \\
\hline$\Delta \ln \mathrm{GDP}$ & -8.371 & $(0.000)^{* * * *}$ & $I(1) \quad[1]$ & -9.337 & $(0.000)^{* * * *}$ & $I(1) \quad[3]$ \\
\hline$\Delta \ln \mathrm{K}$ & -3.480 & $(0.040)^{* *}$ & $I(1) \quad[1]$ & -8.505 & $(0.000)^{* * * *}$ & $I(1) \quad[6]$ \\
\hline$\Delta \ln \mathrm{L}$ & -11.670 & $(0.000)^{* * *}$ & $I(1) \quad[0]$ & -11.622 & $(0.000)^{* * * *}$ & $I(1) \quad[9]$ \\
\hline$\Delta \ln \mathrm{TTR}$ & -3.753 & $(0.020)^{* *}$ & $I(1) \quad[0]$ & -3.753 & $(0.000)^{* * * *}$ & $I(1) \quad[0]$ \\
\hline$\Delta \ln \mathrm{FDI}$ & -6.071 & $(0.000)^{* * *}$ & $I(1) \quad[0]$ & -6.064 & $(0.000)^{* * * *}$ & $I(1) \quad[2]$ \\
\hline$\Delta \ln \mathrm{GOV}$ & -6.044 & $(0.030) * *$ & $I(1)$ & -5.513 & $(0.000)^{* * * *}$ & $I(1) \quad[6]$ \\
\hline$\Delta \ln \mathrm{CPI}$ & -7.077 & $(0.000)^{* * *}$ & $I(1) \quad[0]$ & -6.699 & $(0.000)^{* * *}$ & $I(1) \quad[8]$ \\
\hline
\end{tabular}

Note: $* *$ and $* * *$ denote significance at $5 \%$ and $1 \%$, respectively. $\Delta$ denotes the first-difference operator.

\subsection{Evidence of Causal Flow between Tax Revenue and Economic Growth}

We now turn our attention to the Toda-Yamamoto causality test, having established the order of integration of the variables. Since the maximum order of integration of the variables is one, it implies that $d_{\max }=1$. As the next step, we determine the optimal lag to be included in our augmented VAR model. We achieve this by employing the AIC, SBC, Hannan-Quinn information criterion (HQC), and the Final Prediction Error (FPE). All but SBC selected an optimal lag of 2 to be included in the empirical model (see bottom of Table 4). Thus, $m=2$. From these choices, it means that our parsimonious $V A R$ is of order 3 [i.e. $V A R(3)$ ].

Before jumping to examining the direction of causal flow between tax revenue and economic growth, it is imperative to perform some portmanteau tests to ensure that our VAR process is stable and free of serial correlation. The last column of Table 4 reports the inverse of the root 
of each equation in the $\operatorname{VAR}(2)$ system. It is quite obvious that these values are all greater than unity, implying that the $\operatorname{VAR}(2)$ is structurally and dynamically stable (see Table 4). A further evidence of stability of the system can be established by ocular inspection of Figure 1 in the appendix. Indeed, the plots of cumulative sum of recursive residuals are all within the stable region (see Figure 1). The last row of Table 4 reports the test for serial correlation. Here, the chi-squared value of 681.630 with a p-value of 0.540 indicates strongly that the $\operatorname{VAR}(2)$ system is unlikely to suffer from serial correlation (see Table 4).

Next, we estimate the augmented $\operatorname{VAR}(3)$ system and perform the Toda-Yamamoto test for causality. To keep tractability of our results, we only report the relevant estimates, namely: (i) the causality between tax revenue and economic growth; and (ii) the causal influence of the remaining variables on tax revenue and economic growth. ${ }^{2}$ These estimates are reported accordingly as "Main Results" and "Other Results" in Table 4. We find strong evidence that tax revenue Granger causes economic growth in Ghana but not the other way round. This is shown by a Wald-statistic of 7.8 with a corresponding p-value of 0.02 (see Table 4). This finding therefore strengthens the existing finding on the important role of tax revenue in economic growth such as Ola (2001), Jhingan (2004), Musgrave and Musgrave (2004), and Bhartia (2009). Our results are also in line with the theory. Most government expenses are being funded by revenue collected from taxation. If such expenses are well-directed to building productive infrastructure, refurbishing existing infrastructure, and financing research and development, revenue from taxation will certainly stimulate economic growth.

The final analysis involves the influence of the control variables on tax revenue and economic growth. We find causal flows from labour, capital, and FDI to economic growth in Ghana (see Table 4). These evidences are in line with the existing literature as well. Countries with larger labour and capital stocks, as well as FDI experience faster growth than

\footnotetext{
${ }^{2}$ The remaining results are available upon request.
} 
those with smaller ones. In addition to these causal evidences, we find labour and government expenditure to Granger cause tax revenue in Ghana (see Table 4).

Table 4: Results for Causality Test

\begin{tabular}{llll}
\hline & Wald-statistic [p-value] & & Inverse Roots \\
\hline Main Results & & & \\
& LNGDP & LNTTR & \\
$\ln$ GDP & NA & $0.150[0.930]$ & 1.071 \\
$\ln$ TTR & $7.800[0.020]^{* *}$ & NA & 1.071
\end{tabular}

\section{Other Results}

\begin{tabular}{|c|c|c|c|}
\hline $\ln \mathrm{L}$ & $16.400[0.000]^{* * *}$ & $6.400[0.028]^{* *}$ & 1.138 \\
\hline $\ln \mathrm{K}$ & $5.260[0.034]^{* *}$ & $0.540[0.760]$ & 1.138 \\
\hline $\ln \mathrm{GOV}$ & $0.280[0.870]$ & $5.700[0.031]^{* *}$ & 1.270 \\
\hline $\ln \mathrm{FDI}$ & $8.081[0.019]^{* *}$ & $0.720[0.700]$ & 1.270 \\
\hline $\ln \mathrm{CPI}$ & $0.370[0.830]$ & $1.100[0.570]$ & 1.557 \\
\hline Lag Selection & $\mathrm{HQC}=2$ & $\mathrm{SBC}=1$ & $\mathrm{FPE}=2$ \\
\hline Serial Correlation & Chi-squared & {$[0.540]$} & \\
\hline
\end{tabular}

Note: ** and *** denote, respectively, $5 \%$ and $1 \%$ level of significance. NA denotes non-applicable.

\section{Conclusion}

Taxation and economic growth have complex linkages both theoretically and empirically. The complexity stems from the very nature of taxes themselves. Whereas a certain rate of taxes may be necessary to raise the needed wherewithal to finance growth-enhancing projects, a tax rate beyond the optimal level can have distortionary effects on both the demand and the supply-side of the economy. Thus, both the theory and the empirics are divisive on the nature of the influence of taxation on economic growth. Regardless of this complexity, there is one thing certain: taxation influences economic growth. This paper explores the causal influence of tax revenue on economic growth in Ghana. Our point of departure from the existing studies lies in the fact that we examine causality instead of the 
impact. The causality analysis performed in this paper builds on a multivariate setup, allowing for key control variables such as capital, labour, government expenditure, and inflation to intermediate the nexus between tax revenue and economic growth. Such a rich environment can overcome variable omission bias; thus allowing for efficient estimates of the test statistics of the Granger causality. In addition, we employed the Toda-Yamamoto test instead of the canonical Granger causality test to avoid pre-testing bias. Using a quarterly dataset which spans the period 1986Q1-2014Q4, we found strong evidence of unidirectional causal flow from tax revenue to economic growth in Ghana. This finding agrees with the existing finding that taxation can influence economic growth. The policy implication is quite clear. Ghana is a net borrower since the country regularly suffers from budget deficits. The policymaker can implement policies that enhance the tax scope in order to increase the revenue from taxation. For a country whose economy has a large share of black market activities, such a policy may be challenging to implement. Thus, such policies will require collective efforts from the policymaker and the players in the economy. To induce people to buy into these kinds of policies, the policymaker must first embrace accountability of the revenue raised from taxation. Productive government spending will appeal to the players of the Ghanaian economy whereas unproductive and unaccountable government spending will not. 


\section{References}

Aryeetey, E., and Fosu A. K. (2005). Economic growth in Ghana: 1960-2000, Draft Chapter at African Economic Research Consortium (AERC) Growth Project Workshop, Cambridge.

Afonso, A., and Furceri, D. (2010). "Government Size, Composition, Volatility and Economic Growth.” European Journal of Political Economy, 26(4):517-32.

Alesina, A. and Perotti, E. (1996). "Fiscal Adjustment in OECD Countries: Composition and Macroeconomic Effects”, NBER Working Paper No.5730, Cambridge, Mass.: NBER.

Andrews, D. W. K. (1991). "Heteroskedasticity and Autocorrelation Consistent Covariance Matrix Estimation," Econometrica, 59(3), 817-858.

Arseneau, M., Dao, N. H. and Godbout, L. (2011). "Impact of Tax Mix on Economic Growth: New Evidence from OECD Panel Data", in way of publication.

Asiedu, E., and Lien, D. (2004). Capital controls and foreign direct investment. World Development, 33(5), 368-379.

Barro, R. (1995). “Determinants of Economic Growth”, Cambridge, Mass, MIT Press.

Bergh, A. and Karlsson, M. (2010), "Government size and growth: Accounting for Economic Freedom and Globalization”, Public Choice, 142, 195-213.

Bhartia, H. L. (2009). Public Finance. 14th Ed. Vikas Publishing House PVT Ltd, New Delhi.

Borensztein, E., De Gregorio, J., and Lee J. W. (1998). How does foreign investment affect economic growth? Journal of International Economics, 45(1), 115-135.

Dackehag, M. and Hansson, A. (2012). "Taxation of income and economic growth: An Empirical Analysis of 25 rich OECD countries", Working Paper 2012:6, Department of Economics, Lund University, March. 23.

De Gregorio, J. (2006). Economic growth in Latin America: From the disappointment of the twentieth century to the challenges of the twenty-first. (Working Papers. No. 377) Central Bank of Chile.

Devaranjan, S., Swaroop, V. and Zou, H. (1996). "The Composition of Public Expenditures and Economic Growth”, Journal of Monetary Economics, 37, 313-344.

Domar, E. D. (1946). Capital expansion, rate of growth, and employment. Econometrica, 137-147. 
Easterly, W., and Rebelo, S. (1993). Fiscal policy and economic growth. Journal of Monetary Economics, 32, 417--458.

Ebrahimi, P. and Vaillancourt, F. (2012). "L'impact du mix fiscal sur la croissance économique des provinces canadiennes, 1981-2010”, Project report, CIRANO, 2013RP-03, February, Montréal.

Engen, E.M. and Skinner, J. (1992). Fiscal policy and economic growth, NBER Working Paper No. 4223. Cambridge, Mass.: NBER.

Engen, E. M. and Skinner, J. (1996). Taxation and economic growth, National Tax Journal, 49, 617-642.

Erbaykal, E., and Okuyan, H. A. (2008). Does inflation depress economic growth? Evidence from Turkey. International Research Journal of Finance and Economics, 17, 41-48.

Esso, L. J. (2010). Cointegration and causality between financial development and economic growth: Evidence from ECOWAS countries. Journal of Economics and International Finance, 2(3), 036-048.

Fölster, S. and Henrekson, M. (1999). Growth and the public sector: A critique of the critics, European Journal of Political Economy 15, 337-358.

Fölster, S. and Henrekson, M. (2006). "Growth effects of government expenditure and taxation in rich countries, A reply”, European Economic Review, 50, 219-221.

Fosu, A. K. (1990). Exports and economic growth: The African case. World Development, $18(6), 831-835$.

Fosu, A. K., and Aryeetey, E. (2008). Ghana's Post-Independence Economic Growth: 19602000. The Economy of Ghana-Analytical Perspectives on Stability, Growth and Poverty, James Currey, Suffolk.

Fosu, O. A., and Magnus, F. J. (2006). Bounds testing approach to cointegration: an examination of foreign direct investment trade and growth relationships. American Journal of Applied Sciences, 3, 2079--2085.

Gandolfo, G. (1981). Qualitative analysis and econometric estimation of continuous time dynamic models. New York: North-Holland Publishing.

Granger, C. W. J. (1969). Investigating Causal Relations by Econometric Models and Crossspectral Methods. Econometrica 37 (3): 424-438. 
Hansson, P. and Henrekson, M. (1994). A new framework for testing the effect of government spending on growth and productivity, Public Choice 81, 381-401.

He, Z. and Maekawa, K. (1999). On spurious Granger causality. Economic letters, 73(3), 307-313.

Jhingan, M. L. (2004). Monetary Economics. 6th Ed. Vrinda Publications (P) Ltd, Delhi, India.

Kargbo, S. M., and Adamu, P. A. (2010). Financial development and economic growth in Sierra Leone. Journal of Monetary and Economic Integration, 9(2), 31-61.

Koester, R. B., and Kormendi, R. C. (1989). Taxation, aggregate activity and economic growth: cross-country evidence on some supply-side hypotheses. Economic Inquiry, 27, 367-386 .

Lee, Y. and Gordon, R. (2004). "Tax structure and economic growth", Journal of Public Economics, 89, 1027-1043.

Leibfritz, W, Thornton, J. and Bibee, A. (1997), "Taxation and Economic Performance", OECD Economics Department Working Paper, No. 176.

Levine, R., and Renelt, D. (1992). "A Sensitivity Analysis of Cross-Country Growth Regressions.” American Economic Review 82 (4): 942-63.

Mansouri, B. (2005). The Interactive Impact of FDI and Trade Openness On Economic Growth: Evidence from Morocco. Paper presented at the 12th Economic Research Forum (ERF) Conference, Cairo.

Mascagni, G., Moore, M., and McCluskey, R. (2014). Tax revenue mobilization in developing countries: issues and challenges. European Parliament, EXPO/B/DEVE/2013/35, April.

McDermott, C. J. and Wescott, R. F. (1996), “An Empirical Analysis of Fiscal Adjustments", IMF Working Paper, No. 59, Washington D.C.: IMF.

Musgrave, R. A. and Musgrave, P. B. (2004). Public Finance in Theory and Practice. Tata McGraw Hill, New Delhi, India.

Mutaşcu, M. I., and Dănuleţiu, D. C. (2011). Taxes and economic growth in Romania. A VAR approach. Annales Universitatis Apulensis Series Oeconomica, 13(1), 94-105.

Myles, G. D. (2009). Taxation and economic growth. Fiscal Studies, 21, 141--168. 
Ola, C. S. (2001). Income tax law and practice in Nigeria. HEB-Heinemann Educational Books.

Padovano, F., and Galli, E. (2001). Tax rates and economic growth in the OECD countries. Economic Inquiry, 39, 44--57.

Phillips, P. C. B. and Perron, P. (1988). "Testing for Unit Roots in Time Series Regression," Biometrika, 75, 335-346.

Ram, R., and Ramsey, D. D. (1989). Government capital and private output in the United States: additional evidence. Economics Letters, 30(3), 223-226.

Romer, C. D., and Romer, D. H. (2010). The macroeconomic effects of tax changes: Estimates based on a new measure of fiscal shocks. The American Economic Review, 100, 763--801.

Said, S. E. and Dickey, D. (1984). "Testing for Unit Roots in Autoregressive MovingAverage Models with Unknown Order," Biometrika, 71, 599-607.

Sarel, M. (1996). "Nonlinear Effects of Inflation on Economic Growth", IMF Staff Papers, 43, 199-215.

Skreb, M. K. (1999). “Tax policy and economic growth", Economic Trends and Economic Policy, No. 73, 62-121.

Solow, R. M. (1956). A contribution to the theory of economic growth. The Quarterly Journal of Economics, 70, 65--94.

Stock, J. H., and Watson, M. W. (1988). Testing for common trends. Journal of the American Statistical Association, 83, 1097-1107.

Swan, T. W. (1956). Economic growth and capital accumulation. Economic Record, 32, 334361.

Tanzi, V., and Zee, H. H. (1997). "Fiscal Policy and Long-run Growth." International Monetary Fund Staff Papers, 179-209. Washington, DC: International Monetary Fund.

The Bank of Ghana Macroeconomic Time Series Database. Available on https://www.bog.gov.gh/index.php?option=com_wrapper\&view=wrapper\&Itemid=231. Last accessed: 01/10/2015.

Toda, H. Y. and Yamamoto T. (1995). Statistical inference in vector autoregressions with possibly integrated processes. Journal of Econometrics, 66, 225-250. 
World Bank, (2015). World Development Indicators. http://data.worldbank.org/products/wdi Last accessed: 01/10/15

Yamada, H. (1998). A note on the causality between exports and productivity: an empirical reexamination. Economics Letters, 61: 111-4.

\section{APPENDIX}

\section{Figure 1: Cumulative Sum of Recursive Residuals}

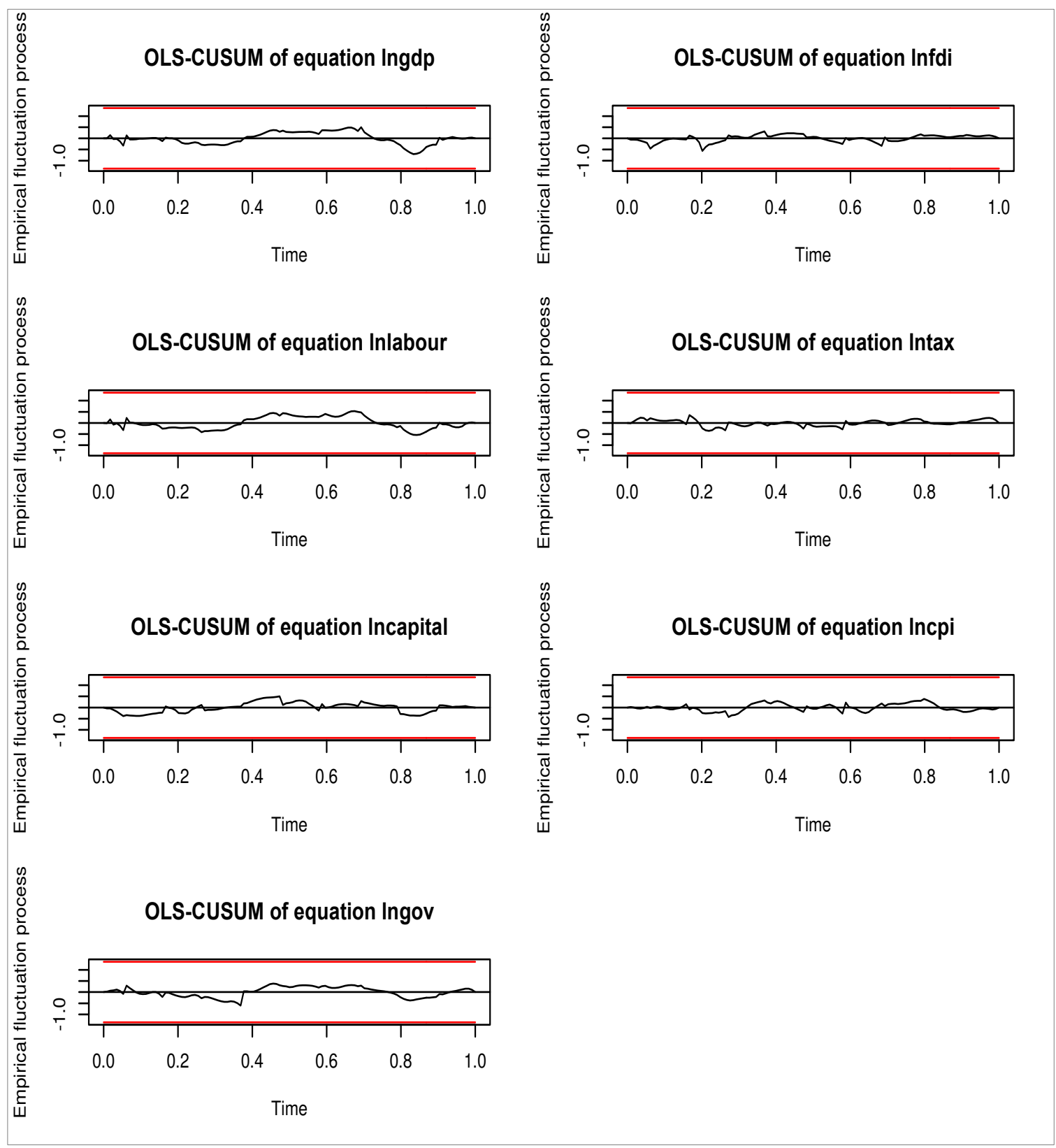

